\title{
ASSESSMENT OF SEASONAL VARIABILITY FOR WIND SPEED AND SIGNIFICANT WAVE HEIGHT USING SATELLITE ALTIMETER OVER MALAYSIAN SEAS
}

\author{
M. N. Uti ${ }^{1}$, A. H. M. Din ${ }^{1,2,3 *}$ and A. H. Omar ${ }^{1}$ \\ ${ }^{1}$ Geomatics Innovation Research Group (GIRG), faculty of Built Environment and Surveying, Universiti Teknologi Malaysia, 81310 \\ Johor Bahru, Johor, Malaysia. \\ ${ }^{2}$ Geoscience and Digital Earth Centre (INSTEG), Faculty of Built Environment and Surveying, Universiti Teknologi Malaysia, \\ 81310 Johor Bahru, Johor, Malaysia. \\ ${ }^{3}$ Associate Fellow, Institute of Oceanography and Environment (INOS), Universiti Malaysia Terengganu, Kuala Terengganu, \\ Terengganu, Malaysia. - amihassan@utm.my
}

KEY WORDS: Wind speed, significant wave height, Seasonal variations, Satellite Altimeter, Radar Altimeter Database System, Monsoons

\begin{abstract}
:
Malaysia is located in the equatorial region and experienced climate hot, humid and rainy throughout the year. These have brought four monsoon seasons to Malaysia which can be categorised as Northeast monsoon, Southwest monsoon, First-inter monsoon and Second-inter monsoon. Although Malaysia is surrounded by large scale marine resources, the lack of understanding in seasonal variability has affected the spatial and temporal analysis. Thus, this study will highlight the assessment of seasonal variability of wind speed and significant wave height over the Malaysian seas. For more than two decades satellite altimeter data were used to generate a prolonged trend of regional ocean wind speed and significant wave height in order to study the monsoons in Malaysia. A set of wind speed and significant wave height data are compared with the in-situ measurement to validate the accuracy of the wind speed and significant wave height observation using the satellite altimeter. Two selected buoys were using as benchmarks and assessed using the statistical analysis by conducting a root mean square error and a correlation calculation. Seasonal variations assessment is conducted with significance to analyse the monsoon effect towards the wind speed and significant wave height condition. As a result, both ocean parameters present a good value of root mean square error and positive correlation which were 0.7976 (wind speed) and 0.92 (significant wave height), which proves the measurement from satellite altimeter is reliable to use. In addition, the seasonal variation assessment illustrates during the Northeast monsoon, each part of the Malaysian seas experienced with great wind speed and significant wave height.
\end{abstract}

\section{INTRODUCTION}

\subsection{Research Background}

The location of Malaysia at the equatorial region has brought a different climate throughout the year. This region experienced slightly high temperature with about 26-30 degree Celsius and rainy season. The movements of wind from high and low latitudes has changed the condition of Malaysian oceans every year. The main objectives of this research is to assess the climate of wind and wave over the Malaysian seas. The study area is bounded from $0^{\circ} \mathrm{N}$ to $14^{\circ} \mathrm{N}$ (latitude) and $96^{\circ} \mathrm{E}$ to $126^{\circ}$ E (longitude). Two selected buoys located at Sabah Sea (5.83N, $114.39 \mathrm{E})$ and Sarawak Sea $(5.15 \mathrm{~N}, 111.82 \mathrm{E})$ are used as benchmarks as shown in Figure 1. 24 years period (1993 to 2016) of satellite altimeter data are retrieved and validated by comparing it with the in-situ data.

Thus, this paper highlighted the assessment of seasonal variation of wind speed and significant wave height over the Malaysian seas. Malaysia experienced four different types of monsoons which are Northeast monsoon (Nov-Feb), First-inter monsoon (Mar-Apr), Southwest monsoon (May-Aug) and Second-inter monsoon (Sep-Oct). Each monsoon varies due to the movements of wind from the other regions.

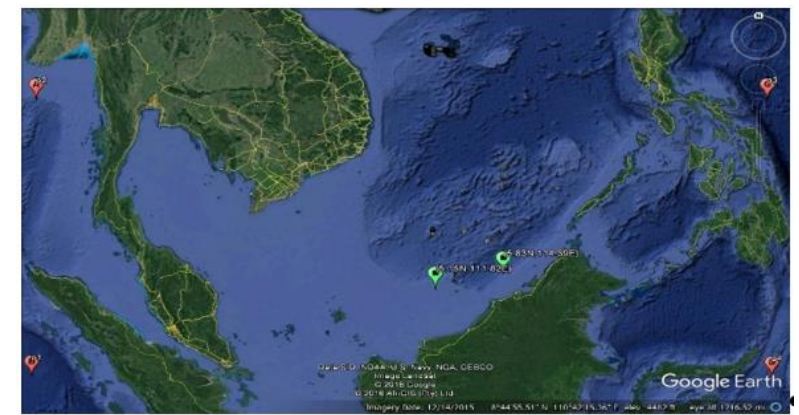

Figure 1. The map of study area (Google Earth, 2018)

\section{THE REVIEW}

\subsection{Satellite Altimeter}

Oceanographic measurements by satellite altimeter have been continuously available through the ERS-1, ERS-2, Topex/Poseidon, Envisat, Jason-1, Jason-2, CRYOSAT, SARAL and Sentinel-3a. These advancement have led to a new era of ocean knowledge through space exploration to provide useful information for sea level, ocean circulation and climate variability studies (Din et al., 2012). The general principle of satellite altimeter is referred to as the reflected signal from the surface and backscattered of the signal.

\footnotetext{
* Corresponding author
} 
Due to the physical properties of the atmosphere and the roughness of ocean surface, the most suitable frequencies used in radar altimeter fall within the range of $2-18 \mathrm{GHz}$ (Chelton $e t$ al., 2001). 'Most satellite altimeters used the $\mathrm{K}_{\mathrm{u}}$-band signal that range from 10.9 to $22.0 \mathrm{GHz}$. All the satellite altimeter data can be downloaded using the Radar Altimeter Database System (RADS) produced with the cooperation of Delft Institute for Earth-Oriented Space Research (DEOS) and National Oceanic and Atmospheric Administration (NOAA). This facility is operated using the internet networking known as Netherlands Earth Observation NETwork (NEONET). The advantage of RADS, is the clients are able to retrieve, process and verify all the altimetry data with accurate and precise measurements (Andersen and Scharroo, 2011). Table 1 presented the available data provided in the RADS.

\begin{tabular}{|c|c|c|c|}
\hline $\begin{array}{c}\text { Altimet } \\
\text { er }\end{array}$ & Phase & Time & Cycles \\
\hline \multirow[t]{5}{*}{ ERS-2 } & $\mathrm{C}$ & 14 Apr $1992-20$ Dec 1993 & $083-101$ \\
\hline & $\mathrm{D}$ & 24 Dec 1993 -10 Apr 1994 & $103-138$ \\
\hline & $\mathrm{E}$ & 10 Apr 1994 - 28 Sep 1994 & $139-140$ \\
\hline & $\mathrm{F}$ & 28 Sep $1994-21$ Mar 1995 & $141-143$ \\
\hline & G & 24 Mar 1995 - 02 Jun 1996 & $144-156$ \\
\hline \multirow[t]{3}{*}{ TOPEX } & $\mathrm{A}$ & 25 Sep $1992-11$ Aug 2002 & $001-364$ \\
\hline & $\mathrm{B}$ & 10 Sep $2002-08$ Oct 2005 & $369-481$ \\
\hline & $\mathrm{N}$ & 11 Oct $2002-20$ Sep 2002 & $365-368$ \\
\hline $\begin{array}{c}\text { POSEID } \\
\text { ON }\end{array}$ & A & O1 Oct 1992 - 12 Jul 2002 & $001-361$ \\
\hline ERS-2 & A & 29 Apr 1995 - 04 Jul 2011 & $000-169$ \\
\hline \multirow{3}{*}{$\begin{array}{c}\text { JASON- } \\
1\end{array}$} & $\mathrm{~A}$ & 15 Jan 2002 - 26 Jan 2009 & $001-260$ \\
\hline & $\mathrm{B}$ & 10 Feb $2009-03$ Mar 2012 & $262-374$ \\
\hline & $\mathrm{C}$ & 07 May $2012-21$ Jun 2013 & $001-260$ \\
\hline \multirow{2}{*}{$\begin{array}{c}\text { ENVIS } \\
\text { AT-1 }\end{array}$} & $\mathrm{B}$ & 14 May $2002-22$ Oct 2010 & 006- 094 \\
\hline & $\mathrm{C}$ & 14 May $2002-22$ Oct 2010 & $095-113$ \\
\hline \multirow{2}{*}{$\begin{array}{c}\text { JASON- } \\
2 \\
\end{array}$} & $\mathrm{~A}$ & 04 Jul 2008 - 02 Oct 2016 & $000-303$ \\
\hline & $\mathrm{B}$ & 13 Oct $2016-04$ Dec 2016 & $305-310$ \\
\hline $\begin{array}{c}\text { CRYOS } \\
\text { AT }\end{array}$ & A & 14 Jul 2010 - 04 Dec 2016 & $004-086$ \\
\hline \multirow[t]{2}{*}{ SARAL } & A & 14 Mar 2013 - 04 Jul 2016 & $001-035$ \\
\hline & $\mathrm{B}$ & 04 Jul 2016 - 04 Dec 2016 & $036-040$ \\
\hline $\begin{array}{l}\text { JASON- } \\
3\end{array}$ & A & 01 Jan 2016 - 04 Dec 2016 & $000-020$ \\
\hline
\end{tabular}

Table 1. Available data provided in Radar Altimeter Database System (RADS, 2017).

\subsection{Ocean wind}

There are two main parameters regarding ocean wind, which are wind speed and wind direction. Ocean wind varies from north to south of the Earth. This movement is affected by the rotation of the Earth and the motion of atmosphere from north hemisphere to the south hemisphere. The wind motion from different has hemisphere brought different seasons to Malaysia. This is the reason for the occurrence of monsoon in Malaysia.

\subsection{Ocean wave}

Three basic characteristics of ocean wave include wave formation, wave dimension and significant wave height. The ocean sea wave is quantified by phases and amplitude being formed based on their location, wind direction and type of water sources (Farah Ellyza, 2016). The accumulation of waves in open sea is basically known as wave spectrum as shown in Figure 2.

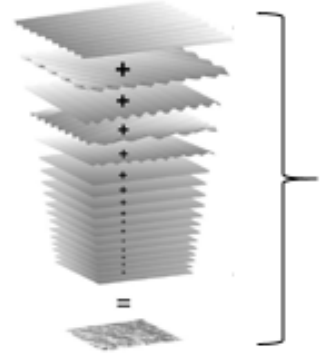

Wave spectrum consist with wave from different directions, periods, phases and amplitudes.

Figure 2. The generation of wave spectrum (Holthuijsen, 2007).

Three components of wave that defined the wave dimensions are height, length and period. Wave height is defined as the vertical distance measured from the trough to the crest of the wave while, wave length is a distance measured between crests or (troughs) as shown in Figure 3. Wave period is the time elapsed between the passing of successive crests or (troughs).

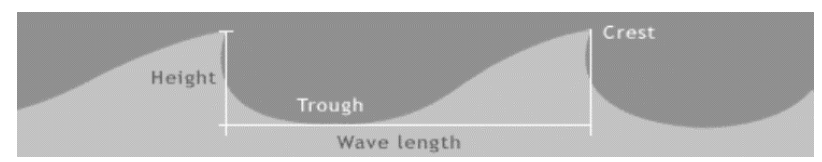

Figure 3. Example of wave dimensions (National Weather Service, 2017)

\subsection{Relationship of wind and wave}

Waves that are generated from the wind blowing over the sea surface are known as wind waves (Mitsuyasu, 2015).The typical wavelength produced by these wind waves is $60-150 \mathrm{~m}$ depending on the strength of the wind forces towards the ocean surface. The factors that affect the wind wave generation are wind strength, wind duration and fetch. Fetch can be defined as the uninterrupted distance over which the wind is blowing without changing directions. Figure 4 illustrates the formation of waves by the winds.

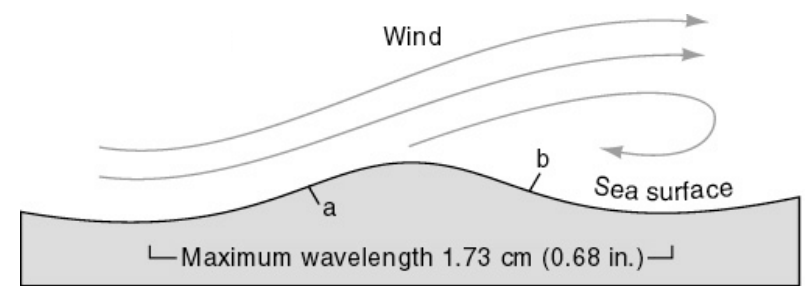

Figure 4. Formation of wind waves (Oceanography, 2015)

\subsection{Monsoon}

Monsoon is a type of season that occurred most of the time in south and east of Asia including Malaysia. Theoretically, monsoon is occurred due to the movement of the air from the sea and land. Two important factors are applied in this theory which is density and pressure. During cold season, the land experienced lower temperature than the ocean, therefore the density and the pressure of the land is higher, resulting in windblown from land to sea. In hot season, the same situation will be reversed, and monsoon is occurred with the existence of seasonal change of wind direction. 
2.5.1 Southwest monsoon: During summer, Asian continent experienced high temperature, therefore producing a low pressure region, leading the air from the Indian Ocean to flow towards the land. This is called southwest monsoon. In Malaysia, Southwest monsoon is occurred in the early of May until end of August and brought a slightly wet season throughout the months.

2.5.2 Northeast monsoon: Opposite to the southwest monsoon, the Asian continent experienced high pressure during the winter season. Northeast monsoon brought a rainy season to most places in Malaysia and occurs from November until end of February. Wind from South China Sea with the combination of cold air outbreaks from Siberia region has blown towards Malaysia region and produced 10 to 30 knot winds.

1.6.3 Transition monsoon: Transition monsoon, also known as inter-monsoon has occurred twice a year. The period from March to April is known as First-inter monsoon and September to October as Second-inter monsoon. The movement of winds from both northeast and southwest regions are very slow and occur in a very short period of time in which the wind movements fluctuate and became slow (Masserah and Razali, 2016).

\section{DATA AND METHODS}

Before this assessment is conducted, a data validation is performed in order to verify the measurements of wind speed and significant wave height data from the satellite altimeter are reliable to use. Thus, a collocation method is used to compare the observation of ocean parameter from the satellite altimeter with the in-situ measurements. The results are present in a statistical ways by conducting a root mean square error and correlation calculation (Kumar et al., 2015).

After that, further climatology analysis of wind speed is performed to examine the seasonal effect of wind speed and significant wave height over the Malaysian seas.

\subsection{Satellite Altimeter Data}

Several missions of satellite altimeter is used to retrieve the climatology wind speed and significant wave height data through the Radar Altimeter Database System (RADS). The data retrieval corresponds within the study area bounded over the Malaysian seas. A 24 year period of wind speed and significant wave height data is extracted from 1993 to 2016 with $0.25^{\circ} \times 0.25^{\circ}$ resolution. Auto processing were conducted to retrieve 24 years data of wind speed and significant wave height as shown in Figure 5

\subsection{In-situ Data}

Malaysia has less network of moored buoy especially in South China Sea, Celebes Sea, Sulu Sea and Malacca Straits. Thus, this paper only used two selected buoy stations at Sabah and Sarawak Sea regions as provided by an oil and gas company. Same as the previous study, the in-situ data will act as benchmark to assess the accuracy of measurements from other techniques (Yong et al., 2015). Table 2 shows the information of the selected buoys.

\begin{tabular}{|c|c|c|c|c|}
\hline Buoy & $\begin{array}{c}\text { Depths } \\
(\mathbf{m})\end{array}$ & Latitude & Longitude & Data period \\
\hline $\begin{array}{c}\text { Sabah } \\
\text { Buoy }\end{array}$ & 1050 & $5.83 \mathrm{~N}$ & $114.39 \mathrm{E}$ & $\begin{array}{c}\text { Nov 2004-Dec } \\
2007\end{array}$ \\
\hline $\begin{array}{c}\text { Sarawak } \\
\text { buoy }\end{array}$ & 120 & $5.15 \mathrm{~N}$ & $111.82 \mathrm{E}$ & $\begin{array}{c}\text { Jan 2009-Jan } \\
2012\end{array}$ \\
\hline
\end{tabular}

Table 2. Buoys information.

\subsection{Data validation}

Collocation technique is one of the techniques used to validate the reliability of satellite altimeter observation. These validations are conducted to prove the accuracy of the satellite altimeter in providing good spatial and temporal resolution. (Jayaram et al., 2015). According to Chen et al., (2017), in-situ technique such as buoy provides point-based temporal observations for the ocean observation, while satellite altimeter supplies spatial measurements in a simultaneous time with the buoys. Monthly data is used from both ocean parameter in order to analyse the correlation and root mean square error from both measurements.

\subsection{Data assessment}

A seasonal variation assessment is conducted by using climatology data of each ocean parameter. A graphical map of each monsoon is produced in order to analyse the variations of wind speed and significant wave height during monsoons in every part of Malaysian seas including South China Sea, Sulu Sea, Celebes Sea and Malacca Straits.

\section{RESULT AND ANALYSIS}

Wind speed and significant wave height derived from the satellite altimeter is collocated with the ground-truth buoy data. Thus, a linear-regression method is used to perform an intercomparison of measurement from two different techniques.

\subsection{Correlation and RMSE value for wind speed data}

Figure 6 (a) and (b) present the correlation graph and the value of RMSE for wind speed data for buoy located at Sabah Sea and Sarawak Sea respectively.

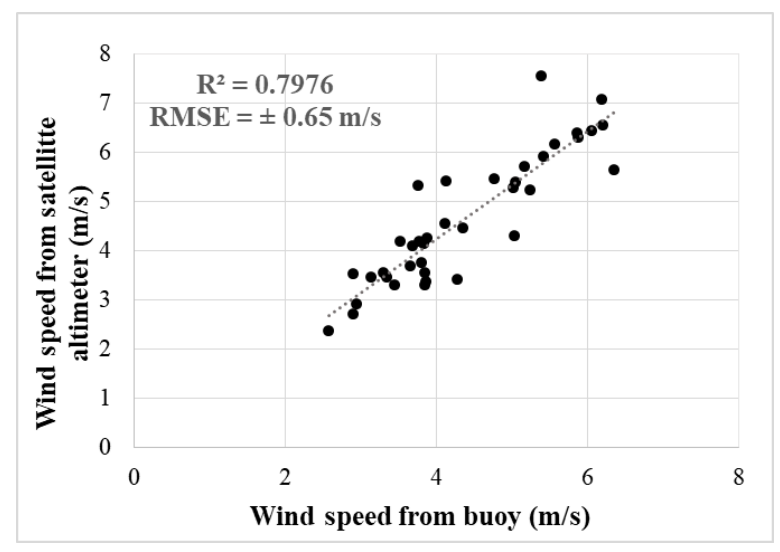




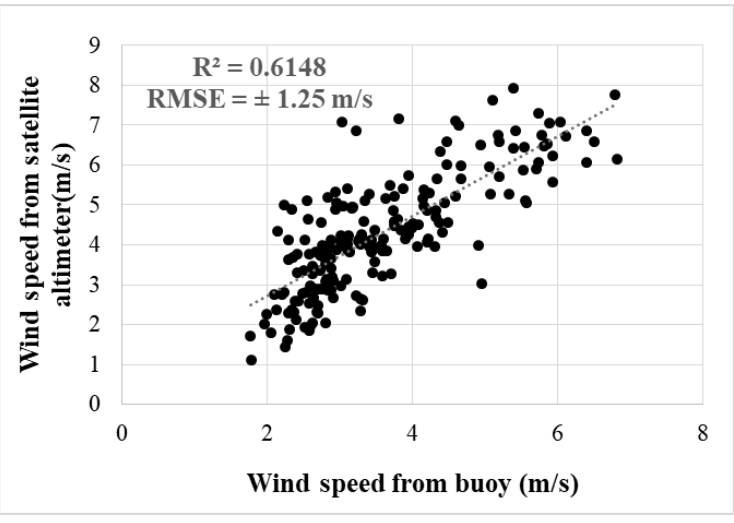

(b)

Figure 6(a) and (b) show the correlation and RMSE value of inter-comparison of wind speed data for point located at Sabah and Sarawak Sea, respectively.

Both of the graphs, present positive value of correlation which were 0.7976 for Sabah Sea and 0.6148 for Sarawak Sea.

\subsection{Correlation and RMSE value for significant wave height data}

Figure 7 (a) and (b) present the correlation graph and the value of RMSE for significant wave height data for buoy located at Sabah Sea and Sarawak Sea respectively.
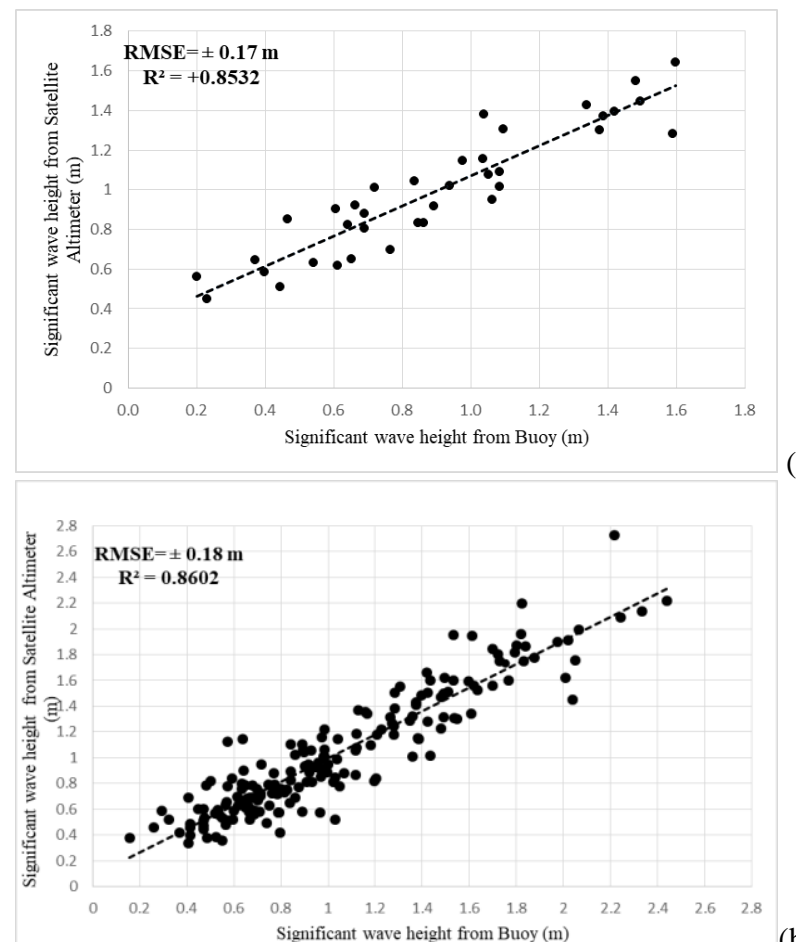

Figure 7(a) and (b) show the correlation and RMSE value of inter-comparison of significant wave height data for point located at Sabah and Sarawak Sea, respectively.

Both of the graphs, present positive value of correlation which were 0.9237 for Sabah Sea and 0.9274 for Sarawak Sea.

\subsection{Wind and wave relationship for each Malaysian seas}

The idea of this assessment is to analyse relationship of wind speed and significant wave height. The stronger the wind speed the greater the significant wave height produced. A trend graph is produced to illustrate the pattern of the wind speed and significant wave height for each sea region. Thus, a correlation value will represent the relationship for both of the ocean parameters as shown in Table 3.

\begin{tabular}{|c|c|}
\hline Sea Region & Correlation \\
\hline South China Sea & 0.84 \\
\hline Sulu Sea & 0.96 \\
\hline Celebes Sea & 0.63 \\
\hline Malacca Straits & 0.04 \\
\hline
\end{tabular}

Table 3. Correlation value of wind speed and significant wave height for each sea region.

Table 3 presents that South China Sea, Sulu Sea and Celebes Sea show a positive correlation value greater than 0.5 , indicating a good ocean parameter relationship. Based on Figure 8, Figure 9 and Figure 10, both of wind speed and significant wave height show almost the same pattern of trendline from January to December in South China Sea, Sulu Sea and Celebes Sea, respectively.

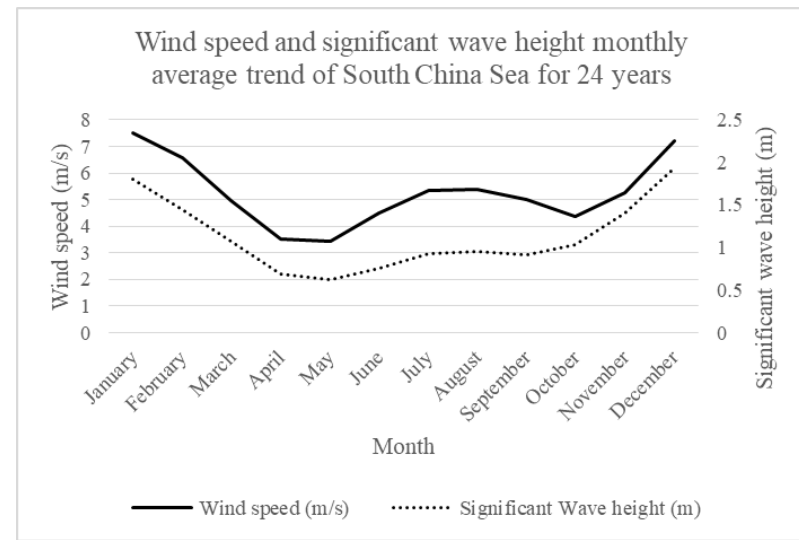

Figure 8. Monthly trend of wind speed and significant wave height for South China Sea.

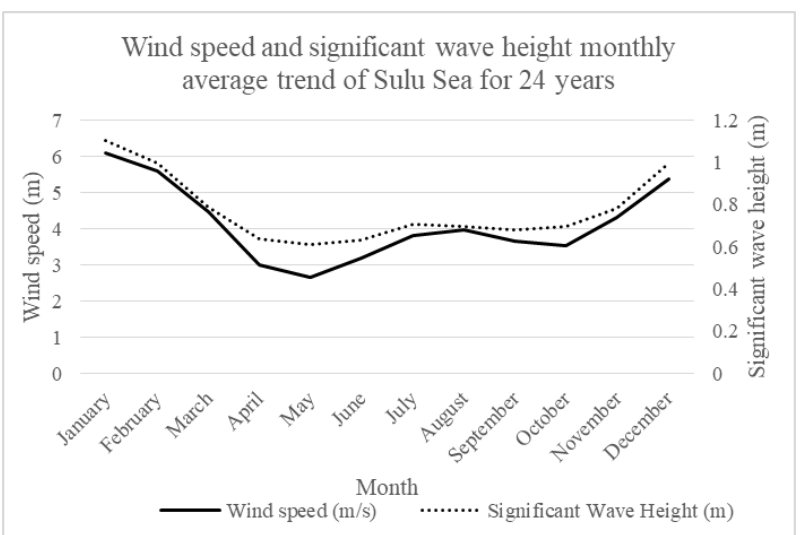

Figure 9. Monthly trend of wind speed and significant wave height for Sulu Sea. 


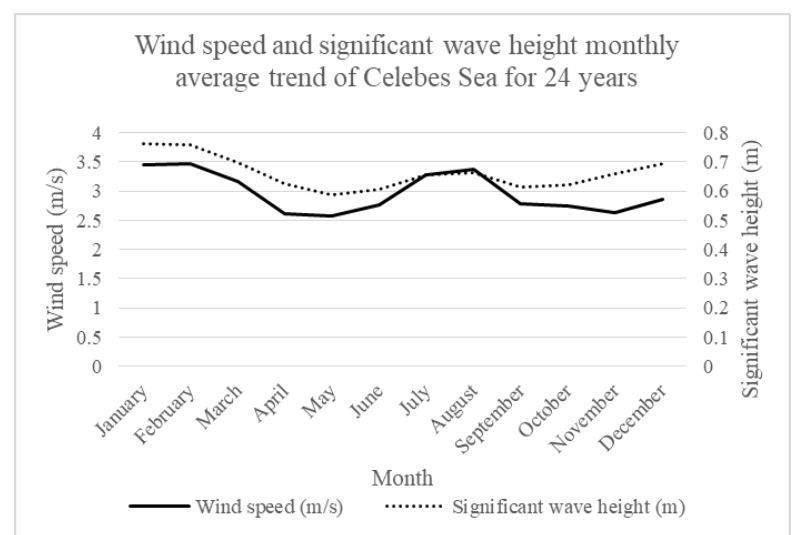

Figure 10. Monthly trend of wind speed and significant wave height for Celebes Sea.

However, the correlation value for Malacca Straits shows the lowest value with 0.04 as shown in Table 3. Figure 11, showed inequality of line pattern for both wind speed and significant wave height. From Figure 11, the significant wave height trend line is not parallel with the wind speed trend line. Malacca Straits is one of the busiest trade passages in the world (Khalid, 2013). It is believed the wave formation is also affected by the movement of the vessels along the straits.

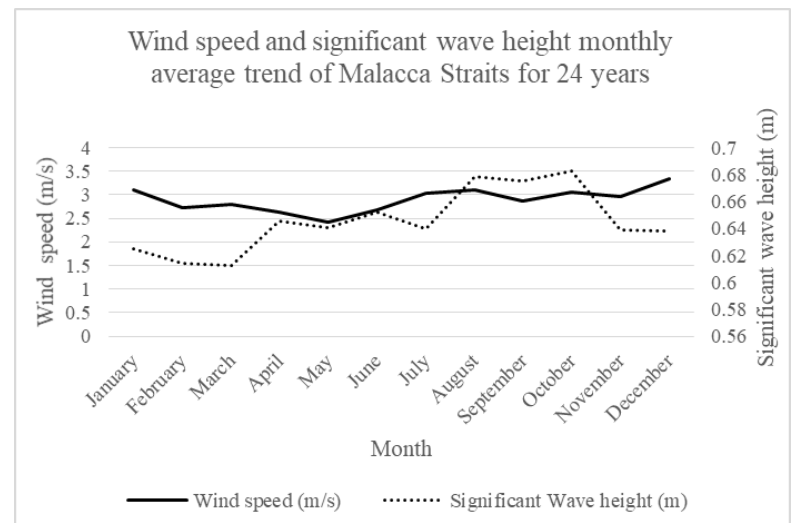

Figure 11. Monthly trend of wind speed and significant wave height for Malacca Straits.

Figure 12 and Figure 13, illustrate the trend of wind speed and significant wave height for Malaysian seas. Both of these figures shows the same trend-line and it is defined that both of the ocean parameters are related to each other.

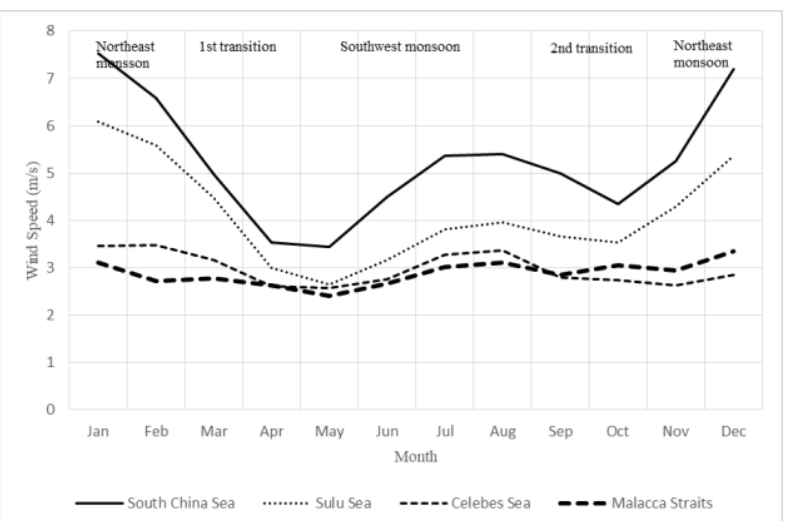

Figure 12. The trend-line of wind speed for each sea regions.

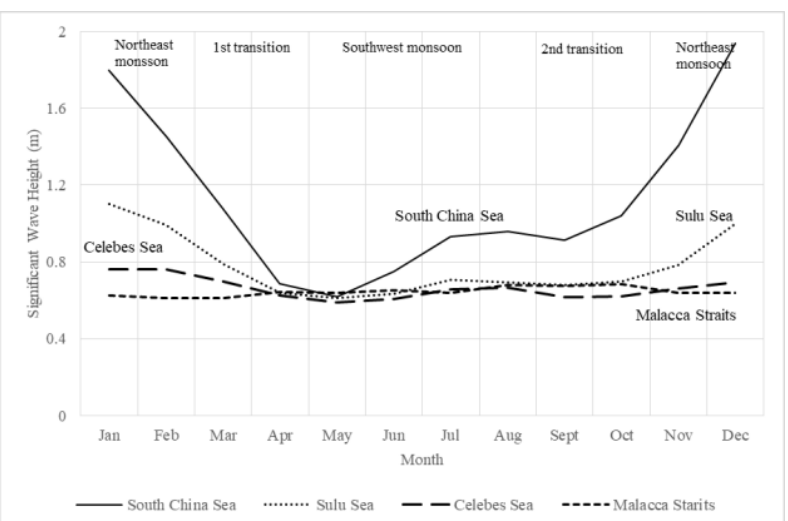

Figure 13. The trend-line of significant wave height for each sea regions.

The graphs present that each sea experienced great significant wave height (Figure 11) during the Northeast monsoon (NovFeb) and lesser during the $1^{\text {st }}$ transition monsoon (Mar-Apr). The same trend is also seen for wind speed data (Figure 10), where the wind speed is stronger during the Northeast monsoon (Nov-Feb) and weaker in $1^{\text {st }}$ transition monsoon (Mar-Apr). However, compared to all sea regions, South China Sea has possessed a stronger wind speed and greater wave height during each monsoon.

This assessment has proved the condition of significant wave height is affected by the strength of the wind speed because wind is also one of the source for wave generation in open sea.

\section{CONCLUSION}

In conclusion, the positive correlation and acceptable RMSE values have proved the measurement of ocean parameter from the satellite altimeter is reliable for seasonal variability studies. The climate assessment of both wind speed and significant wave height present a better understanding of ocean dynamics especially the season variability. Both wind speed and significant wave height are strong during the Northeast Monsson (November- February) and less during the $1^{\text {st }}$ Inter Monsoon (March-April). This paper also highlights, that both wind and wave have significant relationship to each other. This study is very important to provide better ocean dynamic information for the marine sectors such as fisheries, tourism, renewable energy and oil and gas activity.

\section{ACKNOWLEDGEMENTS (OPTIONAL)}

The authors would like to thank to TU Delft, NOAA, Altimetrics LLC for providing the altimetry data through Radar Altimeter Database System. We are grateful to the Ministry of Education (MOE) Malaysia and Universiti Teknologi Malaysia for funding this research under Research University Grant (VOT number: Q.J130000.2527.19H26). 


\section{REFERENCES}

Andersen,O., B., Schrarroo, R., 2011. Range and Geophysical Corrections in Coastal Regions: And Implications for Mean Sea Surface Determination. In Coastal Altimetry.

Chen, C., Zhu, J., Lin, M., et al. 2017. Validation of the significant wave height product of HY-2 Altimeter. Remote Sensing, 9, pp. 1016.

http://dx.doi.org/10.3390/rs9101016.

Chelton, D. B., Ries, J. C., Haines, B. J., Fu, L. L., Callahan, P. S. (2001). Satellite Altimetry. International Geophysics.

Din, A. H. M., Omar, K. M., Naeijie, M., Ses, S. 2012. Longterm sea level change in the Malaysian seas from multi-mission altimetry data. International Journal of Physical Sciences, 7(10), pp. 1694-1712.

Farah Ellyza, H. 2016. Assessment of wave energy resources in Malaysia using satellite altimetry. Doctor of Philosophy (Mechanical Engineering). Universiti Teknologi Malaysia.

Holthuisjen, L. 2007. Waves in oceanic and coastal waters. Cambridge University Press.

Jayaram, C., Bansal, S., Krishaveni, A. S., et al. 2015. Evaluation of SARAL/Altika measured significant wave height and wind speed in the Indian Ocean Region. Journal of Indian Soc. Remote Sensing. http://dx.doi.org/10.1007/s12524-0150488-7.

Khalid, N. (3012). Keep calm and carry on shipping. Maritime Risk International, 2797), pp 14-15.

Kumar, U. M., Swain, D., Sasamal, S. K., Reddy, N. N., Ramanjappa, T. 2015. Validation of SARAL/Altika significant wave height and wind speed observations over North Indian Ocean, Journal of Atmospheric and Solar-Terrestrial Physics, 135, pp. 174-180.

Massesrah, N. K. and Razali, A. M. (2016). Modelling the wind direction behaviours during the monsoon seasons in Peninsular Malaysia. Renewable and Sustainable Energy Reviews, 56, pp 1419-1430.

Mat Nizam, U., Ami Hassan, M. D., Abdullah, H. O. 2017. Reliability of wind speed data from satellite altimeter to support wind turbine energy. International Archives of the Photogram Remote Sensing \& Spatial Sci, 42(4W/5), pp. 215-224.

Mitsuyasu, H., 2015. Reminiscences on the study of wind waves. Proceedings of the Japan Academy, Series B Physical and Biological SciencesI, Vol 9(4), pp. 109-130.

doi: 10.2183/pjab.91.109.

RADS Tudelft. 2017. Satellite Altimeter Data. Retrieved from Radar Altimeter Database System (RADS), DEOS), Dutch. http://rads.tudelft.nt/rads/rads.shtml.

Wave Dimensions (2017). Retrieved June 29, 2018, from https://www.weather.gov/.

Wind Waves (2015). Retrieved June 29, 2018, from http://ksuweb.kennesaw.edu.
Yong, W., Jie, Z., Junmin, M., Jing, W. 2015. A wave energy resource assessment in China's seas based on multi-satellite merged radar altimeter data. Acta Oceanol. Sin, 34, pp. 115125.

Revised August 2018 